
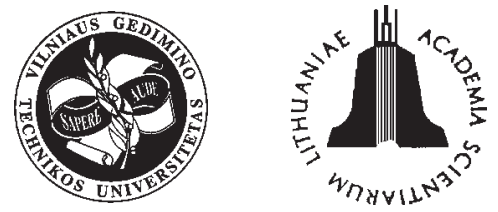

ISSN 1392-3730

JOURNAL OF CIVIL ENGINEERING AND MANAGEMENT

http:/www.jcem.vgtu.lt

2005, Vol XI, No 4, 323-336

\title{
THE FATIGUE BEHAVIOUR OF THE BREATHING WEBS OF STEEL BRIDGE GIRDERS
}

\author{
Miroslav Škaloud and Marie Zörnerová \\ Institute of Theoretical and Applied Mechanics, Academy of Sciences, Prosecká 76, \\ Prague 9, Czech Republic.E-mail: skaloud@itam.cas.cz; zornerova@itam.cas.cz
}

Received 20 Apr 2005; accepted 08 July 2005

\begin{abstract}
The limit state of thin-walled steel girders subjected to many times repeated loading is to a great extent affected by the cumulative damage process occurring in the girder webs "breathing" under the repeated loads. Based on experimental results obtained by the authors at the Institute of Theoretical and Applied Mechanics in Prague, (i) various approaches to the definition of the fatigue limit state of the above girders are discussed, (ii) a number of potential design procedures suggested by other researchers validated and (iii) a set of S-N curves, established by the writers so as to serve as a reliable tool for the fatigue analysis of thin-walled girders with "breathing" webs, presented.
\end{abstract}

Keywords: repeated loads, web breathing, fatigue cracks, failure mechanism, fatigue limit state, S-N curves.

\section{Introduction}

One of the promising trends in the promotion of further headway in steel structures is that towards a broad application of thin-walled plated systems.

It is now generally acknowledged that such thinwalled plated systems, ie systems composed of thin plate elements, represent one of the most economical tendencies in constructional steelwork. This is thanks to the fact that such plate elements, once buckled or otherwise deformed, are able to generate their own "self-defence" against a further deformation. The plate elements then exhibit a very pronounced post-critical reserve of strength that their ultimate strength is significantly larger than their buckling load.

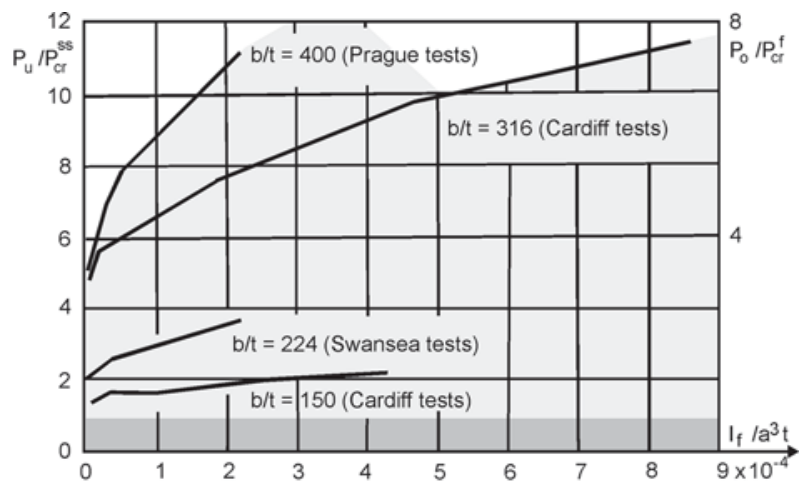

Fig 1. Swansea, Cardiff and Prague shear girder test results
That is why a great attention has been internationally paid to research on the post-buckled behaviour and ultimate strength of slender webs, flanges and other plate elements, the Czech research playing a significant role in this striving.

For example, the authors of this paper and their coworkers spent about three decades in investigating the post-critical reserve of strength and ultimate load behaviour of steel plate girders, box girders, thin-walled columns etc.

Among other things plenty of attention was paid, during the last decades, to the derivation of an ultimate load approach to the design of the webs of steel plate and box girders. It was found out, using both theoretical and experimental investigations, that the (so-called) critical load, determined via linear buckling analysis, was in no relation to the actual ultimate strength of the web, since in a great majority of cases there always existed a very substantial post-critical reserve of strength. This is demonstrated in Fig 1, where the results of tests on shear girders carried out by (i) K. C. Rockey and one of the authors in Swansea and Cardiff and (ii) by the authors of this paper in Prague are plotted. They are given as $V_{u l t} / V_{c r}$ ratios in terms of the flange rigidity parameter $I_{f} / a^{3} t$, because it was found out that flange stiffness very substantially affected the ultimate load of the test girders. On the left-hand vertical axis, the ultimate load is related to the critical load of a web simply supported on all boundaries, while on the right-hand vertical axis the critical load of a clamped web is used in the denominator of the ratio ultimate strength/critical load. But it can be 
seen in the figure that, whether we consider the former or the latter value of the critical load, the post-buckled reserve of strength is always very great.

\section{The web breathing phenomenon}

Although a great part of steel plated structures used in building construction can be listed among structures under the action of quasi-constant loading, this cannot be said about steel bridgework, crane runway girders and similar systems. Such structures are exposed to many times repeated loading. For example, it is not rare that the plate elements (eg the webs) of an important bridge should every year be subjected to hundreds of thousands of loading cycles. Then, if the webs are slender (as they usually are in modern construction) and considering the very great number of loading cycles to which the plate elements are exposed and because of their unavoidable geometric imperfections (particularly of their initial outof-flatness), the webs repeatedly buckle out of their plane. This phenomenon, being now usually termed web breathing, induces significant secondary bending stresses at the boundaries of the web, ie at the web-to-flange and webto-transverse stiffener junctions. Of course, then we can ask the obvious question of whether the breathing phenomenon leads to a significant „erosion“ of the post-critical reserve of strength described above.

It is in the nature of the breathing phenomenon that a pronounced cumulative (fatigue) damage is generated in the girder, this very substantially influencing the limit state of the girder. Fatigue cracks then usually occur in several places (Fig 2) of the breathing web.

When the girder is subjected to predominant bending, a type 1 crack may appear at the toe of the fillet weld connecting the web with the compression flange. Another type of crack the so-called type 4, may develop in a web under the action of predominant shear, namely at the places where the pseudo-diagonal tension field is anchored into the boundary elements of the web panel, this crack then propagating along both the related flange and transverse stiffener.

Furthermore, and independently of the initiation of the aforesaid type 1 crack, fatigue cracks can also occur in the tension zone of the girder: either in the close neighbourhood of the tension flange or in the flange it- self (type 3) or in the vicinity of the end of the transverse stiffener (type 2). However, these types of fatigue cracks are not typical of the breathing phenomenon.

Understandably, a suitably designed experimental investigation is an ideal tool for studying the initiation and propagation of fatigue cracks in breathing webs. That is why an extensive experimental investigation into the problem of web breathing was started in Prague several years ago, which to date comprised 211 tests. Two series of test girders (with various web depths and flange thicknesses) were tested at the Institute of Theoretical and Applied Mechanics of the Czech Academy of Sciences in Prague. This group to date comprised 184 experiments.

At this juncture it should be mentioned that, while the first series of the above tests were conducted on smaller girders, two years ago a series of tests on largesize girders was started at the Institute of Theoretical and Applied Mechanics of the Czech Academy of Sciences in Prague.

Some time ago two other series of girders were tested at Klokner Institute of the Czech Technical University in Prague.

It is perhaps worth noting here that the depth-tothickness ratios of the webs of the Prague test girders were of 175, 200, 250 and 320. Consequently, they ranged from so-called non-breathing webs to very slender ones.

The above research was during its first stage supported by a fruitful co-operation with Cardiff School of Engineering, where another twenty breathing tests were carried out several years ago. The results of the collaborative Prague and Cardiff research were published in a number of papers (see, for example, Škaloud, \& Zörnerová [1] and Škaloud \& Roberts [2]).

In all these tests, the webs of the girders were subjected to many repeated predominantly shear. This was given by the small length of the test girders, which had two square web panels. That is why it was to the benefit of the experimental research that it could completed by six tests conducted at the University of Stuttgart [3] on six large girders having four web panels, whose two outer ones were also subjected to predominantly shear and two inner ones to both bending and shear.

It is also worth mentioning at this moment that, unlike the previous American tests and the aforemen-

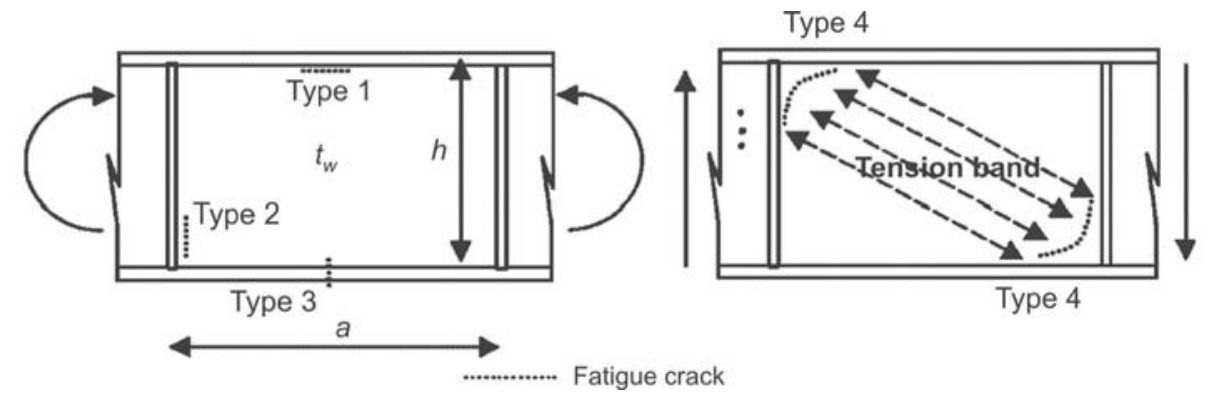

Fig 2. Types of fatigue cracks in a slender web 
tioned Cardiff ones, in which the experiments were stopped when the first observable crack was detected, all Prague tests were conducted to failure. Thus we were able to "map" the whole history of all fatigue cracks from their initiation to the failure of the girder. Thereby we avoided being "fascinated" by the very phenomenon of crack appearance, but were able to study the further development of each crack, to see whether it propagated or stopped, and to find out how far away was the initiation of the first fatigue crack from the fatigue failure of the whole girder.

The most important results of the Prague experimental research can be summarised as follows.

\section{The regime of fatigue crack initiation and growth}

The main impact of the cumulative damage process in the breathing webs of the test girders was the initiation and propagation of fatigue cracks. They developed in crack-prone areas, ie at the toes of the fillet welds connecting the flanges and transverse stiffeners with the web and in zones with maximum ranges of secondary stresses. Just in two cases (out of 211 experiments) a fatigue crack developed inside the breathing web, this being probably due to a notch in the web material. The regime of crack initiation and growth was not simple. In about one half of the test girders, only one fatigue crack (or two cracks in opposite corners of the breathing web) developed, at first advancing along the fillet weld and then (in most cases) turning inside the web and perpendicularly to the tension diagonal in the buckled web. In other cases more fatigue cracks initiated and developed, forming frequently a rather complicated crack system. In it, some of the fatigue cracks joined up or branched out, some of them stopped; and very frequently it was not the first crack that became the main crack and eventually led to the failure of the girder.

Whatever the system of the fatigue cracks in the breathing web, the growth of the cracks was a stable phenomenon with no abrupt change in the rate of crack propagation. Never during our experiments did we observe a kind of the critical crack length phenomenon known from Fracture Mechanics. All our test girders collapsed earlier, when the fatigue crack (or cracks) were long enough to generate one of the failure mechanisms described below.

\section{The failure mechanism}

(a) Most girders exhibited a typical shear failure mode, large buckles developing along the tension diagonal and plastic zones becoming manifest in the girder flanges. In the end, when the main fatigue crack cut most of the tension band, the girders behaved and failed, like ones having a large opening in the web. The cutting off of the tension band was usually materialised by one long fatigue crack, but in several cases (when the cutting crack followed the flange and the transverse stiffener) by a set of short separate cracks.

When one of the transverse stiffeners bounding the breathing web panel was subject to a large point load, as was the case with the central vertical stiffeners of both the Prague and Stuttgart girders, additional fatigue cracks sometimes occurred in the web sheet in the close vicinity of the stiffener, then influencing the failure mechanism described above.

(b) A few girders collapsed as a result of the compression flange buckling vertically when the flange was separated from the web sheet (supporting the flange) by a long enough fatigue crack. This flange buckling occurs under the action of the compression force existing in the flange, and generated by the effect of (i) a bending moment in the girder, and (ii) the truss action in the web, which is subject to predominantly shear and operates in the post-buckled range like a truss.

But in the case studied of plate girders with webs breathing under many times repeated predominantly shear, this type of collapse occurs very scarcely. For example, within the framework of the tests carried out at the Institute of Theoretical and Applied Mechanics in Prague, this happened just twice (out of 184 experiments).

\section{Definition of the fatigue limit state}

Based on an analysis of the experimental results obtained and thanks to having thus "mapped" for all test girders, the whole regime of fatigue crack growth from the initiation of the first fatigue fissure to the failure of the whole girder, the authors were able to verify three potential definitions of the fatigue limit state:

(i) The definition based on the initiation of the first fatigue crack (this definition having recently been suggested by some researchers),

(ii) The definition related to a certain length (for example, to one fifth of web depth) of the main fatigue crack, and

(iii) The definition based on the fatigue failure of the girders.

\subsection{Definition based on fatigue crack initiation}

Some authors have for some time been suggesting that the fatigue limit state of breathing webs should be related to the initiation of the first fatigue crack in the breathing web.

Their approach is understandable, because proceeding in this way we should get a "pure" solution, making it possible always to avoid the presence of any fatigue cracks in breathing webs.

However, in connection with this approach and in the light of our experimental results, the following questions can be raised:

(a) The initiation of which crack?

In our 211 Prague experiments we saw that in a 


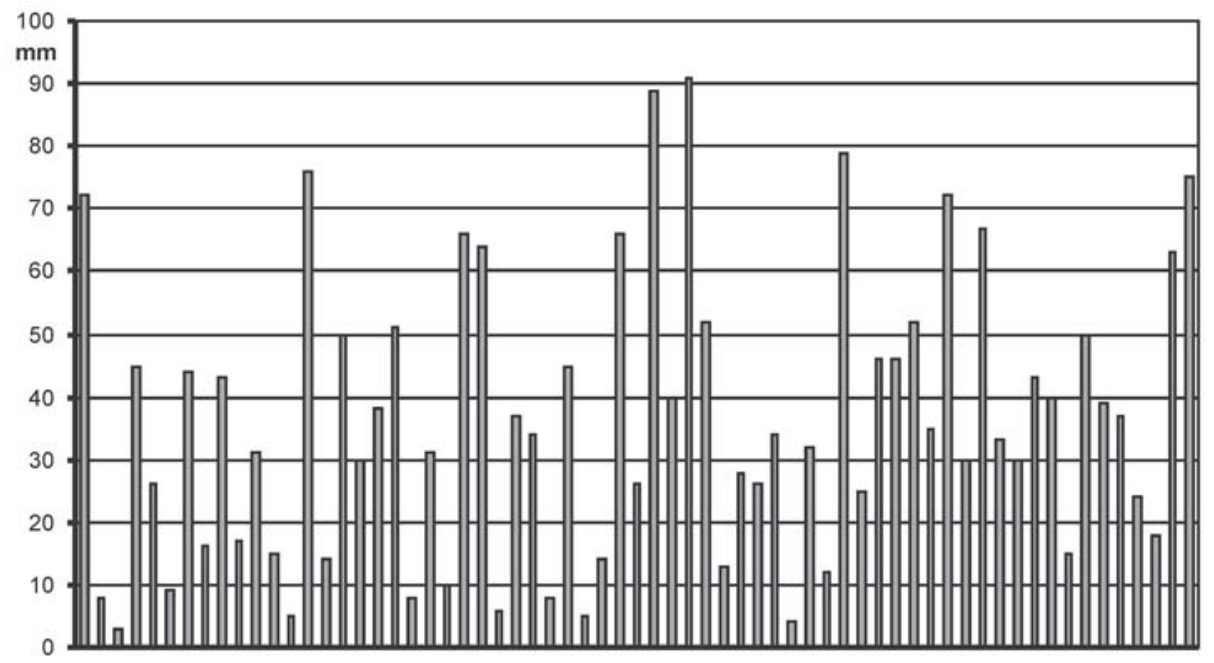

Fig 3. Detected lengths of fatigue cracks

great part of the test girders more than one crack developed and that frequently it was not the first crack that was decisive and "mortal", but another crack or a system of two or three cracks that, through cutting the tension diagonal, evoked the girder failure.

(b) How should we exactly define the initiation of a fatigue crack in a breathing web?

It is well known from the theory of fatigue crack initiation and growth that such cracks proceed from microcracks to small cracks, some of them to large cracks, and one or more of them to main cracks, directly thereafter influencing the failure mechanism of the girder.

But the observations during the more than 210 tests carried out in Prague, which were, of course, influenced by our possibilities of crack detection, were a little different - at least in the initial stage of crack development.

The authors, although paying a great attention to fatigue crack detection, were able to detect these cracks only when they became through-cracks, and their length was large enough to observe the opening and closing of the cracks under the repeated load. In the Prague experiments, these lengths varied from a few $\mathrm{mm}$ to several cm (Fig 3). As before that no cracks were observed, it looked as if the first stage of the fatigue crack had developed rather suddenly.

(c) And even more importantly, what does the appearance of a very small fatigue crack in the breathing web mean for the fatigue failure of the girder?

Usually very little. Just in those cases where the load range is very large (but in practical cases this occurs scarcely), or when the web is very slender and without longitudinal ribs (as was the case with part of our Prague girders, where the web slenderness was of $320-$ but such very slender and longitudinally unstiffened web plates are encountered seldom), the initiation of a fatigue crack is followed by a fast crack growth and a speedy failure of the girder. However, in a great majority of cases the load ranges and web depth-to-thickness ratios are not very large, and then there is a very long way from the initiation of the first fatigue fissure in the web to the collapse of the whole structural system. Very frequently (and we saw this in our experiments) is the number of load cycles at crack initiation only 10-30\% of the fatigue life of the girder.

The above trend is, for the girders tested of the Institute of Theoretical and Applied Mechanics, shown in Fig 4. The history of the growth of the main fatigue crack can be seen in Fig 5, in terms of the ratio shear force range $\Delta V /$ critical shear force $V_{c r}$. As usually several tests were conducted for the same $\Delta V / V_{c r}$ ratio, the results cannot be distinguished on one horizontal line and, consequently, are grouped into "storeys". The large effect of the load range is obvious therefrom.

Considering the aforesaid, we can easily realise that, when the design of breathing webs is based on crack initiation, we can never achieve the same desired safety of all plate girders against their failure. In case of girders with very slender webs and under the action of large load ranges, the reserve of safety after the initiation of the first fatigue crack (ie the difference between failure and crack initiation) is small $(10,20 \%$ or so). On the contrary, for ordinary plate girders, whose webs are practically never so excessively slender, subjected to usually encountered load ranges, the post-crack-initiation safety reserve can be very large (even several hundreds of \%).

\subsection{Definition related to a certain length of the main crack}

It goes without saying that it is easier to detect a certain large enough length of a fatigue crack (for example, equal to one fifth of web depth) than to detect its very initiation. That is why to relate the definition of the fatigue limit state of breathing webs to such a crack length seems to have some advantages. On the other hand, if this crack length is chosen so as to be large enough for detection, but small enough for, if need be, the retrofit- 


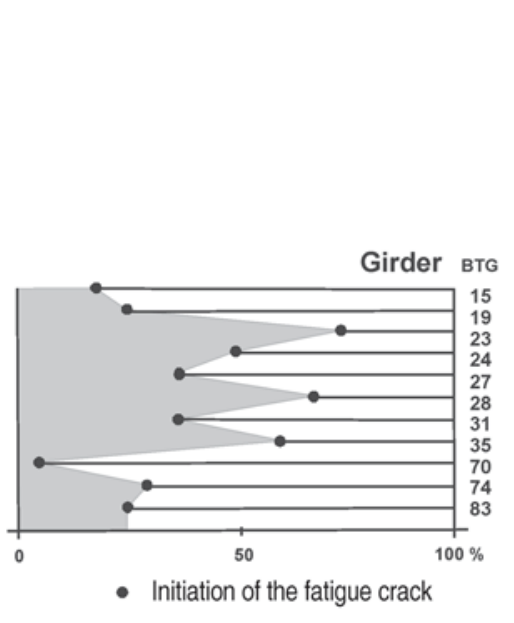

Girders with one fatigue crack

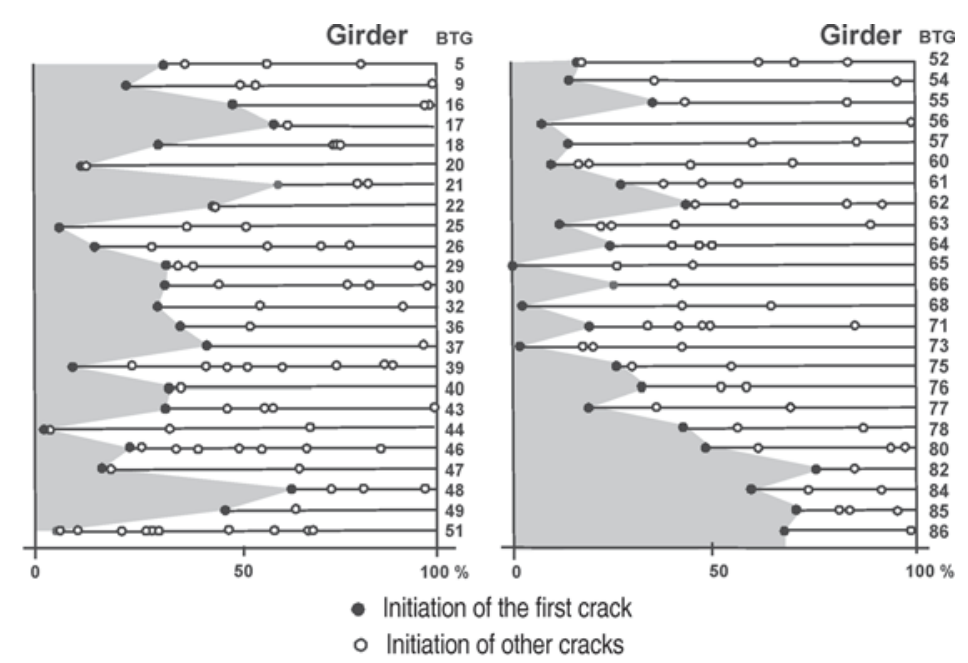

Girders with more fatigue cracks

Fig 4. The initiation of fatigue cracks in the webs of the Prague test girders in relation to their whole lifetime

ting of the girder, we might hope to have achieved a "golden-mean" solution.

However, an examination of Figs 4 and 5 reveals that a fatigue limit state defined in this way is in no balanced relation to the fatigue failure of the girder and, therefore, in this sense does not much improve the situation in comparison with the above approach of crack initiation.

\subsection{Definition based on fatigue failure}

Taking account of the aforesaid, the best approach seems to be to relate the definition of the fatigue limit state of breathing webs to their failure. This means that their lifetime is then equal to the number of load cycles up to the formation of a failure mechanism in the girder.

If, in addition, there is a need for a safeguard against the presence of fatigue cracks in the web under service conditions, this can be introduced in another way (see, for example, below the section on design approaches, namely the design recommendation suggested by R. Maquoi and one of the authors.

\section{Factors influencing the breathing and the fatigue limit state of thin-walled steel girders}

The numerous tests carried out by the authors made it possible to identify those factors which in a signifi-

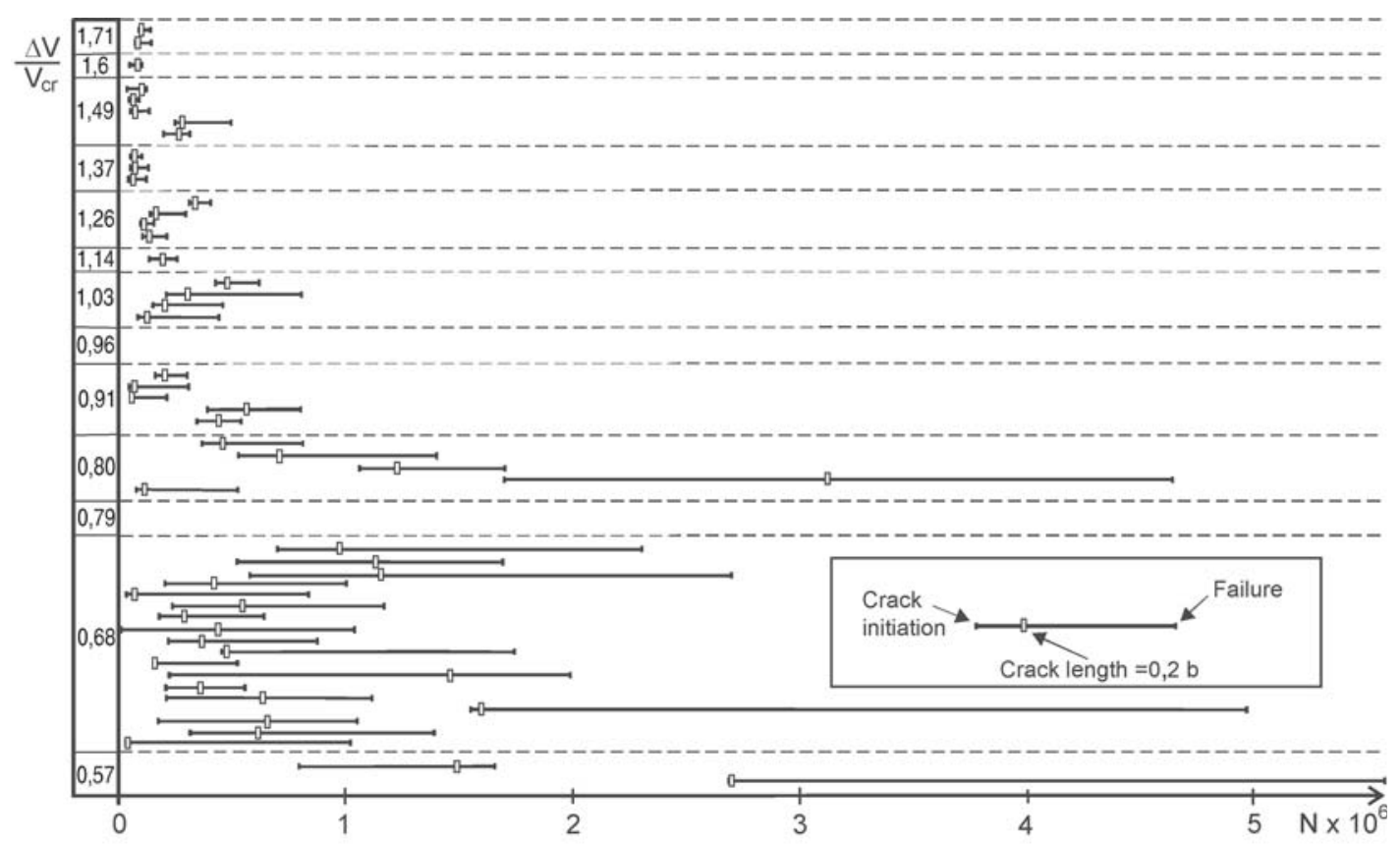

Fig 5. Fatigue crack initiation and growth in terms of $\Delta V / V_{c r}$ 
cant way influence the breathing of the slender webs of steel plate girders.

\subsection{Position of fatigue cracks}

In practically all of the Prague tests, the fatigue cracks initiated at the toes of the fillet welds connecting the breathing web with its peripheral elements, ie with flanges and transverse stiffeners. As for their position, an analysis of the authors' observations shows the following (Fig 6):

(i) When the loading is low, and consequently not significant is also the post-buckled performance of the web, the fatigue cracks can develop at any position along the girder flanges and/or transverse stiffeners, this depending mainly on the shape of the initial curvature of the web. This is understandable in view of the fact that in this case, with the post-critical membrane stresses being small, the stress state in the crack-prone areas is predominantly affected by the bending stresses in the breathing web. These stresses are dependent on the configuration of the buckled surface which under low loads tends to follow (as observed during the writers' experiments) the shape of the initial "dishing" of the web.

(ii) When the loading is high, the post-critical behaviour of the web is pronounced, and the state of stress in the web is very significantly influenced by the membrane stresses in the tension diagonal, which emanates from the corresponding web corners. Therefore, the fatigue cracks initiate near these web corners.

\subsection{Effect of shear force range}

Similarly to other fatigue phenomena, even in the case of web breathing, load (or stress) range is one of the main factors that influence the cumulative damage process and the fatigue limit state. This can be seen in Fig 7, which also shows that when the fatigue lives of the test girders are plotted in terms of the ratio shear force range/critical shear force, thereby indirectly taking

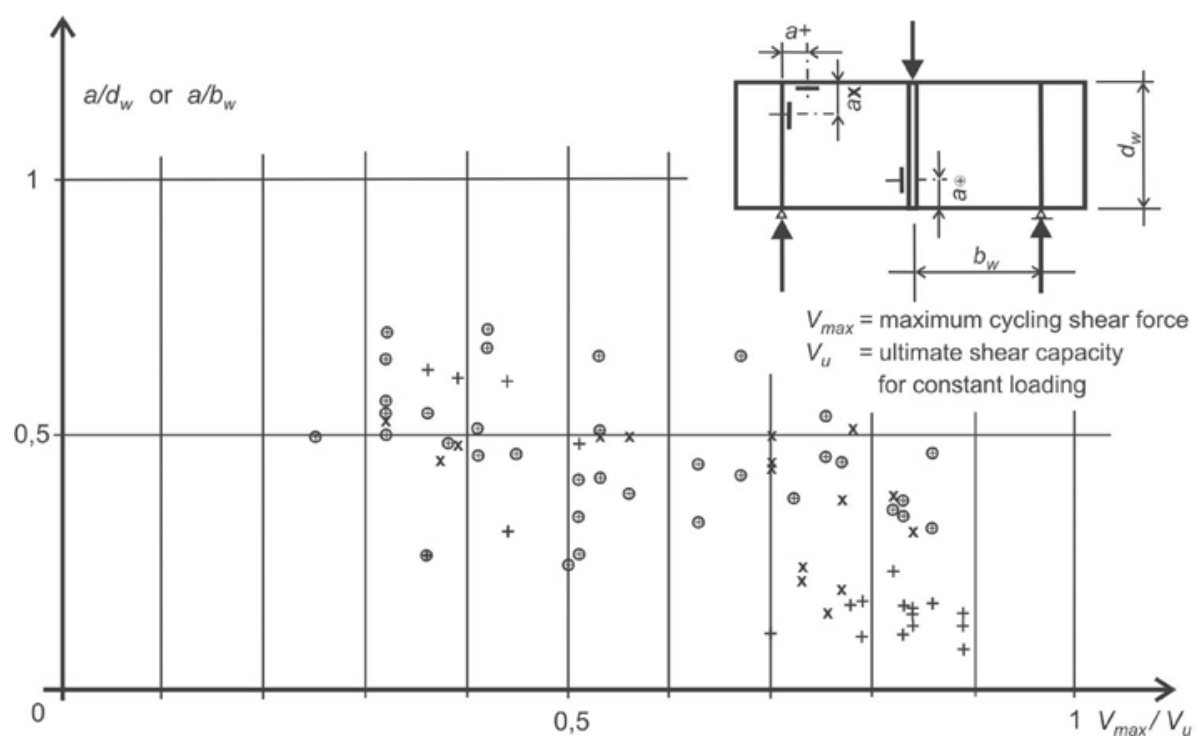

Fig 6. Position of fatigue crack

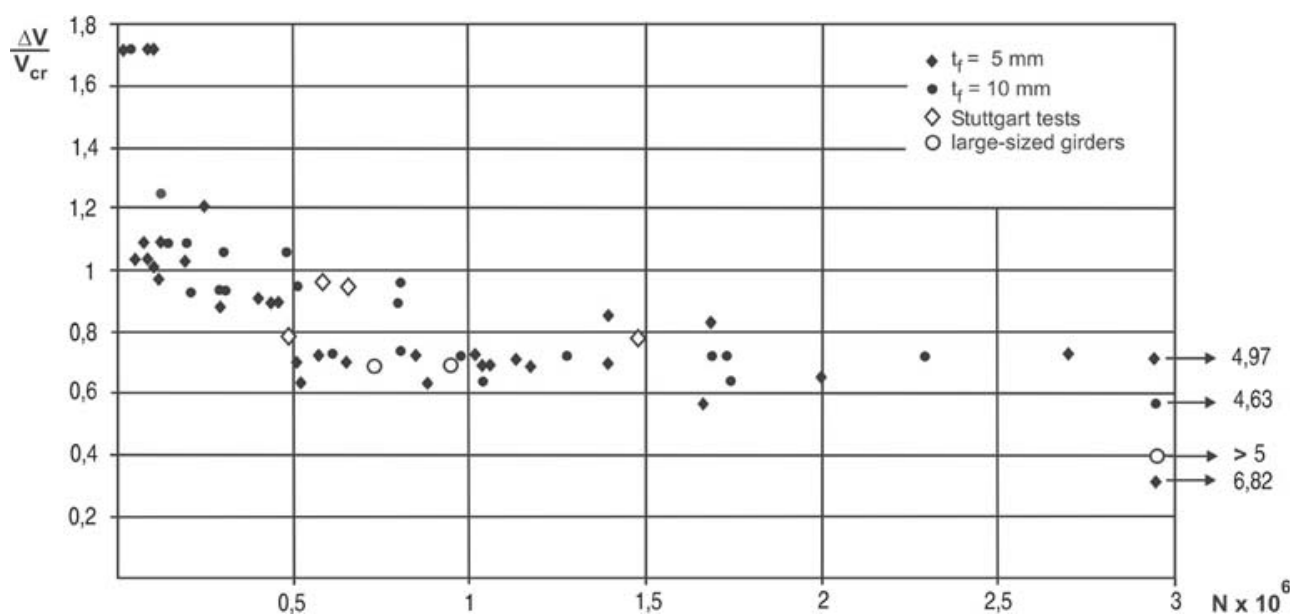

Fig 7. Effect of shear force range 
also account of the difference in web slenderness, the results exhibit a tendency of lying in one band and determining a S-N curve.

\subsection{Effect of shear force ratio}

While the shear force range $\Delta V=V_{\max }-V_{\text {min }}$ always and very considerably affected the lifetime of the test girders, the shear force ratio $V_{\min } / V_{\max }$ did not appear (Fig 8), at least in the domain investigated (ie $\left.V_{\min } / V_{\max }=0-0,67\right)$, to play as important a role.

This may seem rather surprising because the initiation and growth of fatigue cracks also depends, among other things, on the stresses in the vicinity of the fatigue crack root, which are considerably affected by the magnitude of the maximum value of the cycling load. However, these stresses are just one part of the stress state in the crack-prone areas, welding residual stresses, generated by the welding process and independent of the magnitude of loading, being another component of the stress state there.

\subsection{Effect of flange size}

The effect of flange size seems to be significant: when a web breathing under repeated predominantly shear is attached to heavy flanges, the fatigue life of the girder is extended. This phenomenon deserves, however, commenting more.

The influence of the dimensions and rigidity of the flanges is twofold:

(i) the effect of the torsional stiffness of the flanges, which provides the breathing web with restraint and is effective through the whole life of the girder and (ii) the effect of the flexural rigidity of the flanges (which - as demonstrated by the tests carried out by K. C. Rockey and one of the authors - can be very pronounced in the case of webs subjected to unrepeated shear), which can be very important under higher loading, since it considerably influences the stabilising effect of membrane stresses and hence the post-critical behaviour of the web.

Consequently, further research in this line is necessary and is on the agenda of the writers' forthcoming investigations.

\subsection{Effect of initial imperfections}

It is typical of breathing tests that their results exhibit a large scatter. Among other things it follows from this observation that an adequately large number of experiments is indispensable if we want to obtain reliable results (this having also been the reason for the large number of breathing tests conducted to date in Prague).

Probably the main reason for the scatter of the results obtained was the effect of unavoidable initial imperfections in the test girders, in particular that of the initial curvature of the girder web, which varied (in a rather complicated and unpredictable manner)from girder to girder.

The effect of the initial curvature of the girder web is twofold, viz

(i) the effect of the shape of the initial curvature,

(ii) that of the magnitude of the initial curvature.

As for the former, it follows from an analysis of the writers' results that an initial out-of-flatness in several half-waves (inducing also breathing in several halfwaves, ie in a surface with larger curvatures, consequently generating larger secondary bending stresses) is more detrimental than an out-of-flatness in a single half-wave. Of course, this holds only when the loading is not high. When it is high, the buckled pattern ceases to be affine to the shape of the initial curvature and always changes into the typical diagonal buckling configuration.

This is shown in Fig 9, where three pairs of tests are compared. In each of them, the geometry of the test girder and the shear force range are the same for both

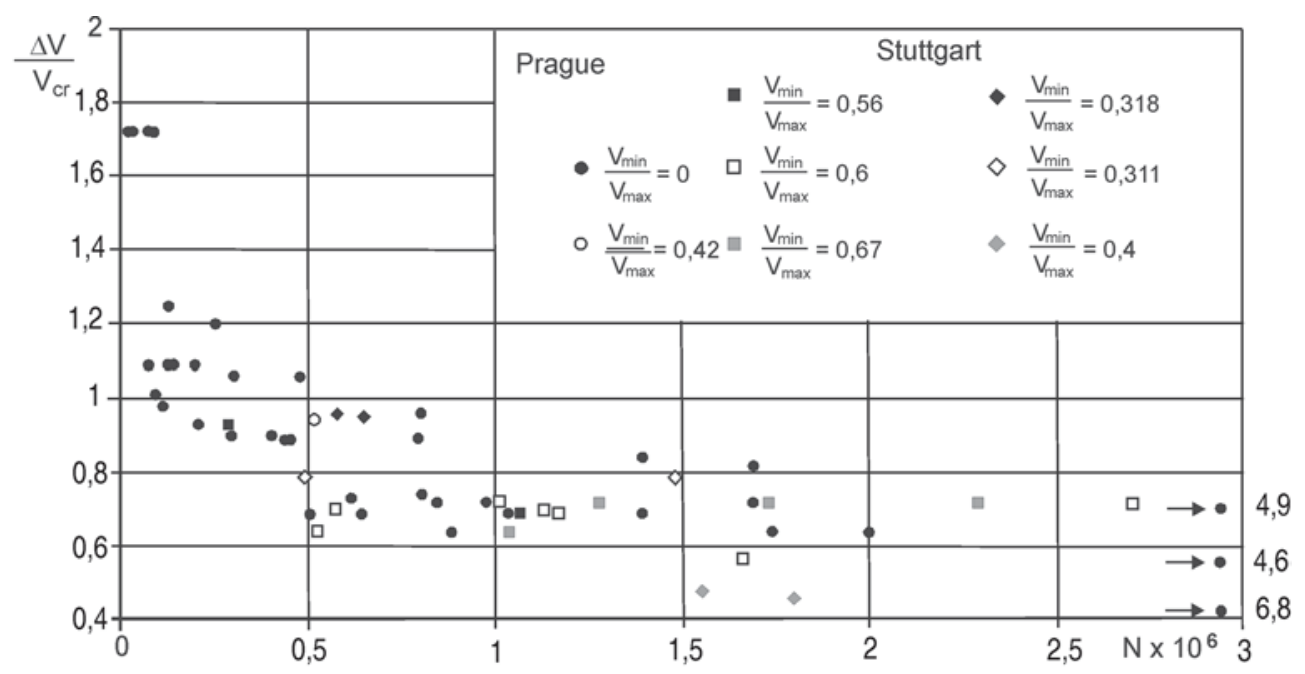

Fig 8. Effect of shear force ratio 


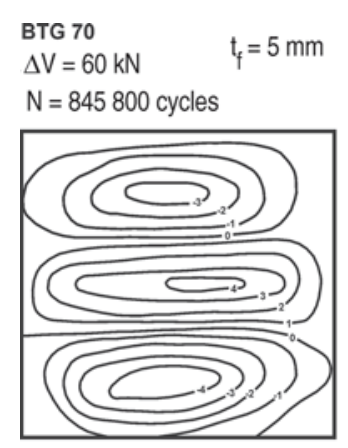

BTG 60
$\Delta \mathrm{V}=60 \mathrm{kN}$

$\mathrm{N}=1999000$ cycles

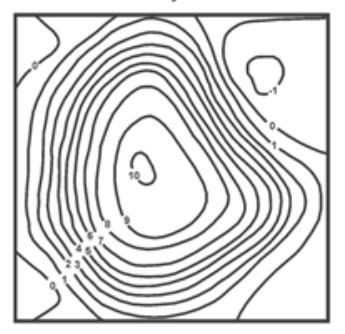

BTG 92

$\Delta \mathrm{V}=150 \mathrm{kN}$

$\mathrm{N}=38500$ cycles

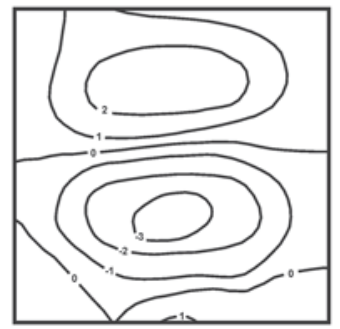

BTG 78

$\Delta \mathrm{V}=60 \mathrm{kN} \quad \mathrm{t}_{\mathrm{f}}=10 \mathrm{~mm} \quad$ BTG 63

$\mathrm{N}=975800$ cycles $\quad \mathrm{N}=1741800$ cycles

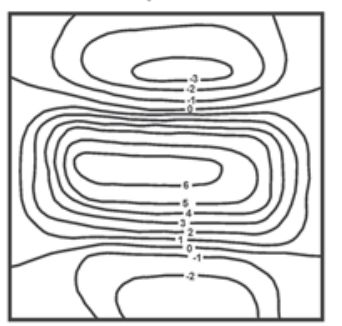

BTG 30

$\Delta \mathrm{V}=150 \mathrm{kN}$

$\mathrm{N}=128300$ cycles

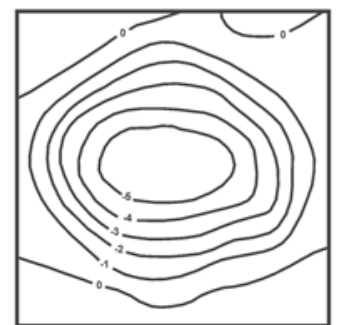

Fig 9. Effect of the shape of initial curvature

girders, but in one of them the initial "dishing" of the web has two or three half-waves, while the other has a single half-wave initial curvature. It can be seen in the figure that the girders of the first group exhibit considerably shorter lifetimes. It was also found out that whenever repeated snap-throughs occurred during breathing of the web (and this happened in $15 \%$ of the Prague breathing tests), thereby enhancing the dynamic aspect of the breathing phenomenon, this frequently led to a significant shortening of the test girder life.

As far as the latter factor, ie the magnitude of the initial curvature, is concerned, the authors' experiments demonstrated that this effect was observable, but less pronounced.

As the Prague experiments showed that initial curvature could play a very important role in the fatigue design of steel girders, a special and extensive sensitivity analysis of the problem was started by Z. Kala, J. Kala, B. Teplý and on of the authors, about whose results and conclusions it was reported in [4].

\subsection{Effect of the quality level of the fillet welds con- necting the breathing web with the girder flanges and stiffeners}

Similarly to other fatigue phenomena, even in the case of web breathing the quality of welding very substantially affects the position of crack initiation and, even more importantly, the length of the lifetime of the girder. This became manifest as early as the first stage of tests carried out in Prague and Cardiff and was proved by all the experimental series that thereafter followed in Prague.

\section{Design approaches}

Having mapped in detail the cumulative damage process in breathing webs, the authors proceeded to establishing a suitable design procedure.

What approaches were available? The main of them were as follows: (i) limitation of web slenderness or of load acting on web, (ii) application of fracture mechanics, (iii) so-called beam analogy, and (iv) S-N curves based on experimental results obtained.

And it is again an experimental investigation which made it possible to assess all of them.

\subsection{Limitation of web slenderness or load}

Two simple and very user-friendly approaches can be contemplated so as to incorporate the impact of web breathing into design:

- In the first of them, the depth-to-thickness ratio of the web is reduced so that all detrimental effects of web breathing can be disregarded.

- In the other, it is the loading acting on the web that is reduced to reach the same objective.

With regard to the former approach, breathing tests on more than 60 girders whose web slenderness was equal to 175 (ie inferior to 180 , which was previously suggested by some other authors as the maximum web depthto-thickness ratio for which the effect of web breathing can be disregarded) were carried out at the Institute of Theoretical and Applied Mechanics in Prague. However, contrary to expectations, these experiments showed that the breathing phenomenon in the respective girders was far from being negligible, fatigue cracks developing in 
most of the girders. Therefore, it follows from these tests that a stronger limitation of web slenderness (ie to slenderness values lower than 175) will be necessary if it is desired to disregard the effects of web breathing in design.

This conclusion is not surprising because web breathing is nothing else than many times repeated web buckling; consequently, all webs prone to buckle are also prone to breathe under repeated loads. Of course, in the case of webs with low depth-to-thickness ratios, the effect of buckling is less significant than with slender webs and, hence, also the impact of web breathing must in this case be less pronounced; and for low enough depthto-thickness ratios it will be entirely negligible. However, further experimental data are indispensable with the view to quantify the above expectation, and this shall be the objective of a new series of tests which are under way at the Institute of Theoretical and Applied Mechanics in Prague.

And how is the situation in regard to the other simple approach, ie to limit the load acting on the web so that, in case of many times repeated loading, the effect of web breathing can be disregarded?

Among numerous fatigue tests conducted to date in Prague, there were also some for which the upper value of the cycling load was inferior to the critical buckling load; nevertheless, the effect of breathing was still pronounced (even though less so than for higher loading) and therefore not negligible. Even this observation is not surprising, since for a web with initial imperfections the critical load, resulting from the linear buckling theory and related to an "ideal" web without imperfections, does not mean much and, therefore, such webs buckle (and, under repeated loads, breathe) even when subjected to loading inferior to the critical load.

\subsection{Application of fracture mechanics}

This approach seems to be very inviting because it looks more "scientific", less costly and time-consuming than experimental investigation. That is why the authors tried to apply it, in cooperation with J. Djubek and R. Kodnar, to the solution of the web breathing problem; see, for example [5].

Although some valuable information resulted from the study, it did not lead to the full solution of the problem, the main reasons being as follows: (i) Unlike the very wide field of mechanical engineering and other structural systems, where fracture mechanics proved to be a powerfull tool for a successful solution of numerous important tasks, in the case of the web breathing problem, we did not have enough reliable information about all factors needed for a successful application of the Paris-Erdogan equation. (ii) Further, and more importantly, the numerous experiments carried out in Prague revealed no critical length phenomenon (which determines the limit state in the optics of fracture mechanics) in the case of breathing webs. Such webs failed earlier, when the main fatigue crack (or cracks) was (were) long enough to generate a failure mechanism in which the girder collapsed like one having a large opening in the web.

\subsection{The beam analogy}

This approach, first applied by Maeda and Okura [6-7], is based on the idea that it is primarily secondary (generated by web breathing) bending stresses at welded web boundaries, perpendicular to these boundaries, that bring about the initiation and propagation of fatigue cracks. These stresses, which are determined via nonlinear analysis of web buckling, due allowance being made for the influence of the initial curvature of the web and of its peripheral elements (ie of the flanges and transverse stiffeners), are used in conjunction with the fatigue strength of the web material at the toes of fillet welds, found out experimentally using simple beam (usually cantilever) elements subject to simple bending. This means that the complex fatigue behaviour of breathing webs is replaced by the much simpler fatigue performance of beam elements perpendicular to the crack-prone web boundary, but on the condition that the bending stresses in the beam element are regarded as being equal to those evaluated by means of the non-linear analysis of the whole web.

It was again Maeda and Okura who, following the above approach, carried out theoretical studies of the secondary bending stresses at welded web boundaries, using non-linear finite element plate analysis. Then they used the results obtained, in conjunction with the fatigue strength of fillet welds, to establish fatigue resistant design criteria for plate girders of practical dimensions.

This approach was then applied by other researchers, and was recently significantly perfected by U. Spiegelhalder [8] and Y. Duchène [9] who, having carried out a very large number of numerical calculations, prepared a great number of design charts and tables.

The above approach, which reminds us of similar approaches used in a number of other cases of the analysis of plated structures (for example, see the strut approach employed in the analysis of the longitudinally stiffened flanges of steel box girders), in a clever way simplifies the complex cumulative damage process in breathing webs. So, why did the writers not apply it in their derivation of a design procedure for breathing webs?

The reasons are twofold:

(i) The available bending stress charts and tables, in spite of being numerous, are still not able to give accurate enough values of bending stresses in the crackprone areas of breathing webs. First, they were established using a simplified assumption for the initial outof-flatness of the web, based on a simple combination of the very first terms of the corresponding Fourier series, while the actual shape of the web initial curvature (depending strongly on the welding process) is frequently 
more complex. As the bending stresses, also those at the web/flange or web/stiffener junction, are very sensitive to the configuration of the web buckled pattern, which is in turn affected (at least until it changes via snap-throughs under higher loads) by the shape of the initial out-offlatness, the actual bending stresses in the crack-prone areas of the web can be even higher than those given in the available charts and tables. Second, not all practically important boundary conditions of the web were considered in the calculations of the bending stresses, eg the effect of the flexural rigidity of girder flanges, which (as demonstrated by numerous tests carried out some time ago by K. C. Rockey and one of the writers in Swansea and Cardiff and then by the writers in Prague) very substantially influences the shape of the buckled surface of the web and, consequently, also the stress state in the web.

(ii) More important is still the other reason; viz there is a great difference between the fatigue behaviour of a simple cantilever bar and that of a plate girder, which is always a system of plate elements. While in the case of a bar one fatigue crack initiates, which then more or less quickly propagates until the fatigue failure of the bar, in the case of a plate girder the system of fatigue cracks, their propagation and role in the failure mechanism are more complex. Usually it is not just one fatigue crack that initiates in the web as a result of its breathing, frequently it is not the first crack which becomes the main crack and thereafter leads, often in interaction with one or two other fatigue cracks, to the formation of a failure mechanism and, consequently, to the fatigue failure of the girder. So, the fatigue strength of cantilever test pieces, which is on the right-hand side of the beam analogy design conditions, cannot adequately describe the fatigue strength of the whole girder.

If it is argued at this juncture that it is the fatigue strength of the whole girder, determined experimentally, that can be introduced into the analysis, why should we, having at our disposal results of the fatigue tests performed on whole girders, at all retreat to the much less accurate beam analogy? In this case it is more pertinent to establish a design procedure based entirely, ie without using a simplified analytical model, on the results of fatigue tests carried out on whole plate girders. And this is the approach employed by the authors.

\subsection{S-N curves established by the writers on the ba- sis of their breathing tests}

The authors follow the general features of the design philosophy proposed by Maquoi and Škaloud [10], according to which two limit states are introduced in the analysis, viz (i), the fatigue limit state, (ii) that of serviceability.

While the fatigue limit state can be related to the failure of the girder (ie to unrepairable damage - which is acceptable in view of the fact that the fatigue limit state can never be attained during the planned life of the girder), the limit state of serviceability should be related to a much more limited, easily repairable degree of damage. In the case of steel girders with breathing webs, this means that, in the course of the useful fatigue life of the girder, either no or very small fatigue cracks can develop such as to be easily kept under control, or easily retrofitted in case of need.

The two limit states can be ascertained directly on the basis of the authors' breathing tests, following the statistic procedure recommended in Appendix $\mathrm{Z}$ of EUROCODE 3. In so doing, the range of the stress state in the breathing web can be measured simply by the range $\Delta \tau_{o}$ of the average shear stress $\tau_{o}$ (=shear force $V /$ web area $A_{w}$ ) in the web. Only those of the writers experiments were considered in which the girder went through all stages of fatigue crack growth until the very failure of the girder.

Before proceeding to the derivation of the S-N curves, let us define the range of their application.

The breathing phenomenon is usually linked with high-cycle fatigue. The frontier, measured by the number $N$ of breathing cycles, between high-cycle and lowcycle fatigue is between $10^{4}$ and $10^{5}$ cycles. As the authors also obtained enough results in this domain, the S$\mathrm{N}$ curves can be regarded as applicable for $N>10^{4}$. As regards the other boundary, ie for high values of $N$, the S-N curves established herebelow hold for all $N<10^{8}$ cycles. For $N=10^{8}$, the $\mathrm{S}-\mathrm{N}$ curves are assumed to reach their threshold value, ie the $\mathrm{S}-\mathrm{N}$ curves are parallel to the $\mathrm{N}$-axis.

As far as web slenderness $\dot{e}$ is concerned, the domain of the application of the S-N curves is identical with the range of the slendernesses of the webs of the girders so far tested at the Institute of Theoretical and Applied Mechanics, ie $175 \leq \lambda \leq 250$. This is also the interval where are the depth-to-thickness ratios of the webs of most steel plated girders subjected to breathing.

A similar statement can be made in regard to web loading. The webs of the writers' test girders were under the action of combined shear $\tau$ and bending $\sigma$, with shear predominating, ie their $\sigma / \tau$ ratios $<1,0$. This means that the S-N curves are applicable to webs subjected to shear or to combined shear $\tau$ and bending $\sigma$ provided $\sigma / \tau \leq 1$. For larger ratios $\sigma / \tau$ will the S-N curves be lower and shall be the objective of further research.

Let us now establish the S-N curves for both limit states.

Inspecting the formulae established herebelow, the reader will realise that they are a little different from those proposed by the writers in their previous contribution [11]. This is understandable in view of the fact that the new formulae have been derived based on a larger number of experimental results and, consequently, are more accurate. 


\subsubsection{Fatigue limit state}

As said above, this limit state is linked with the fatigue failure. The authors' results were in this respect divided into two groups, viz (i) the results obtained by testing girders with web slenderness ratio $\lambda=175$ and (ii) those obtained by testing girders with $\lambda=250$. The results for both groups are plotted in Figs 10 a and 10 b, where also the straight lines giving (a) the average experimental values and (b) the established (via the statistic procedure recommended in Appendix $\mathrm{Z}$ of EUROCODE 3) S-N curves.

Originally it was intended that for intermediate web slendernesses it can be linearly interpolated. But as the difference between the two S-N curves is small, they can with sufficient accuracy be replaced by one curve (see
Fig 11) and one equation, which can then be used for all $175 \leq \lambda \leq 250$.

\subsubsection{Serviceability limit state}

If just one S-N curve is proposed for the fatigue limit state in the domain $175 \leq \lambda \leq 250$, there is an even greater reason for doing the same for the limit state of serviceability, which is related to fatigue crack initiation and for which the authors' tests exhibited a scatter even larger than for fatigue failure. This is not astonishing because crack initiation is very sensitive to initial imperfections of all kinds.

The corresponding experimental results are plotted in Fig 12; the equation given there determines the serviceability limit state S-N curve.

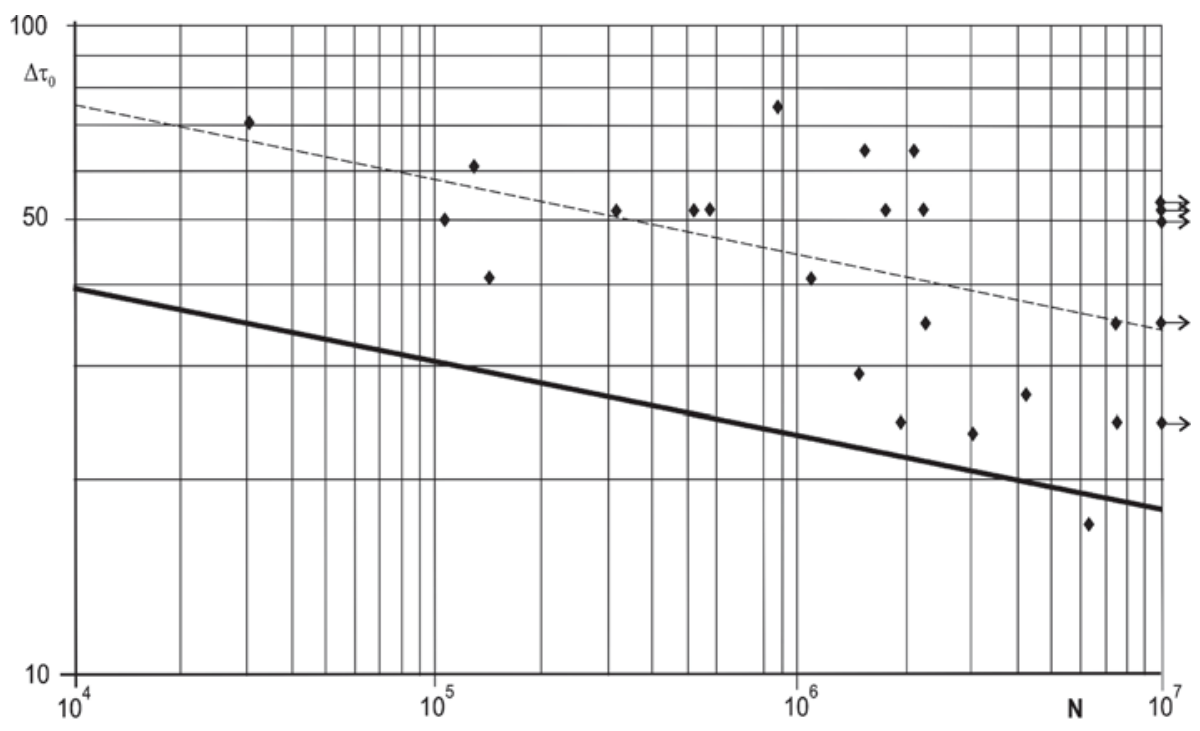

$\log \Delta \tau_{0}=-0,1134385 \log N+2,0578277$

Fig 10 a. Fatigue limit state, web slenderness $\lambda=175$

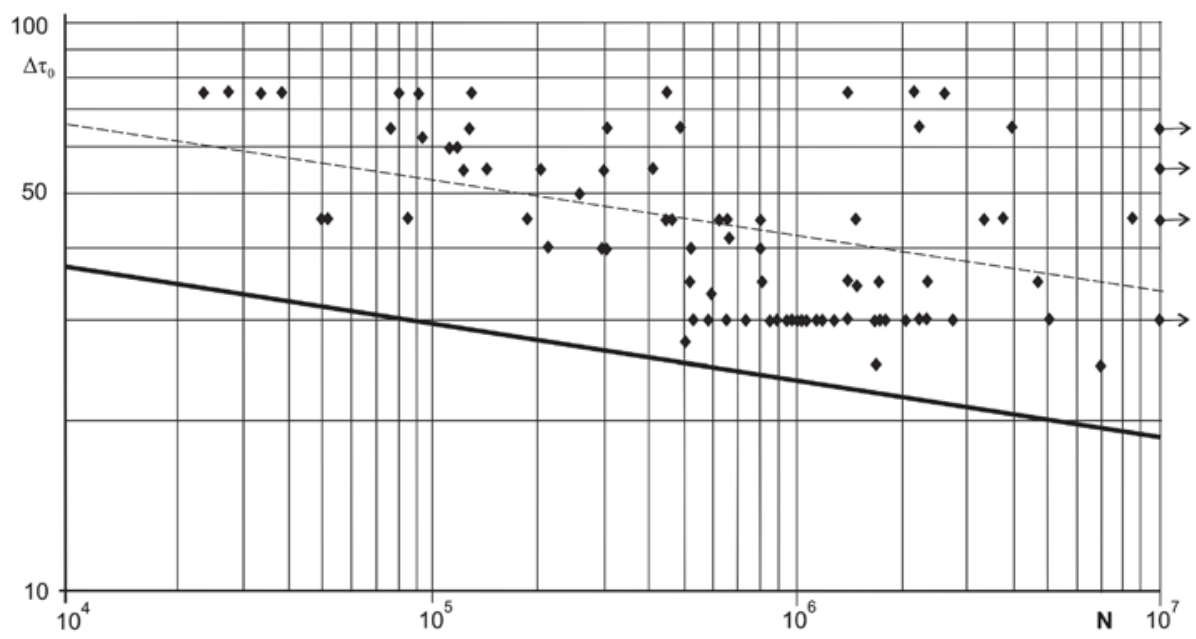

$\log \Delta \tau_{0}=-0,0973038 \log N+1,947754$

Fig 10 b. Fatigue limit state, web slenderness $\lambda=250$ 


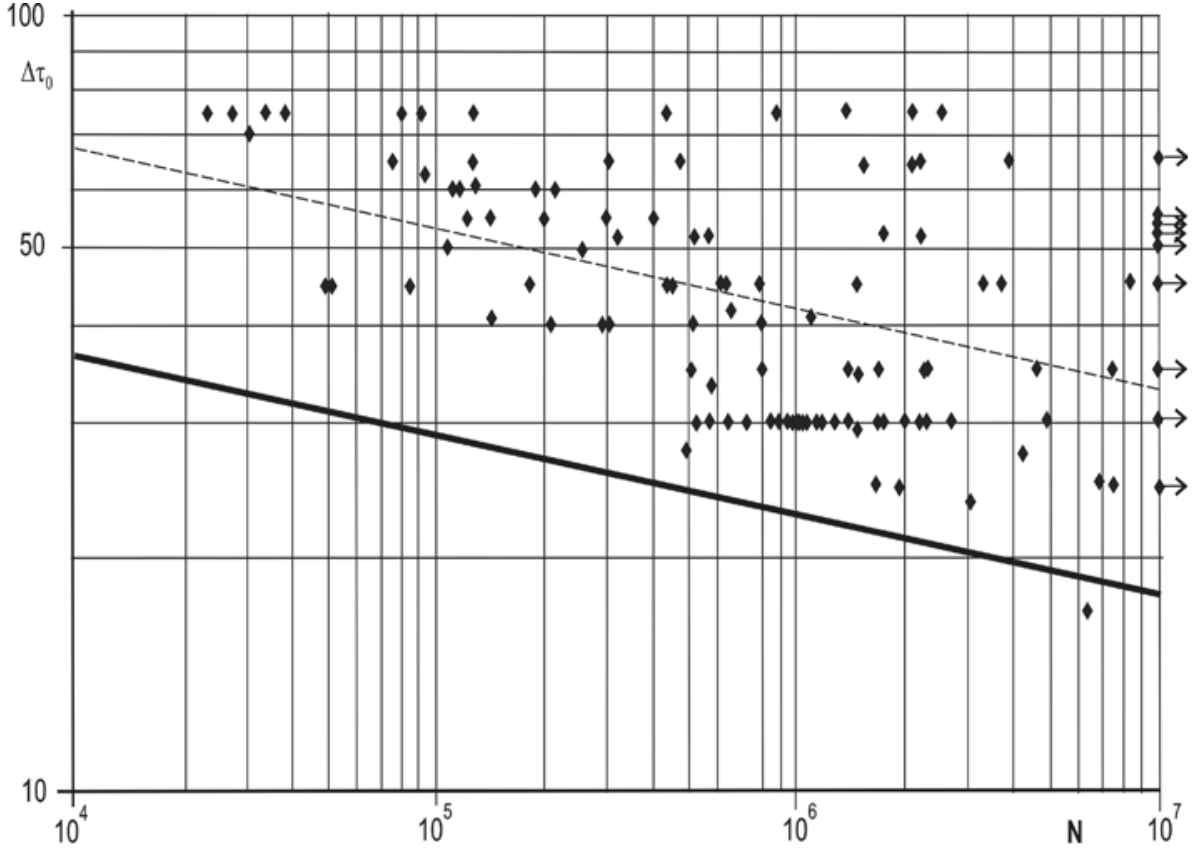

$\log \Delta \tau_{0}=-0,1044158 \log N+1,9884888$

Fig 11. Fatigue limit state, $175 \leq \lambda \leq 250$

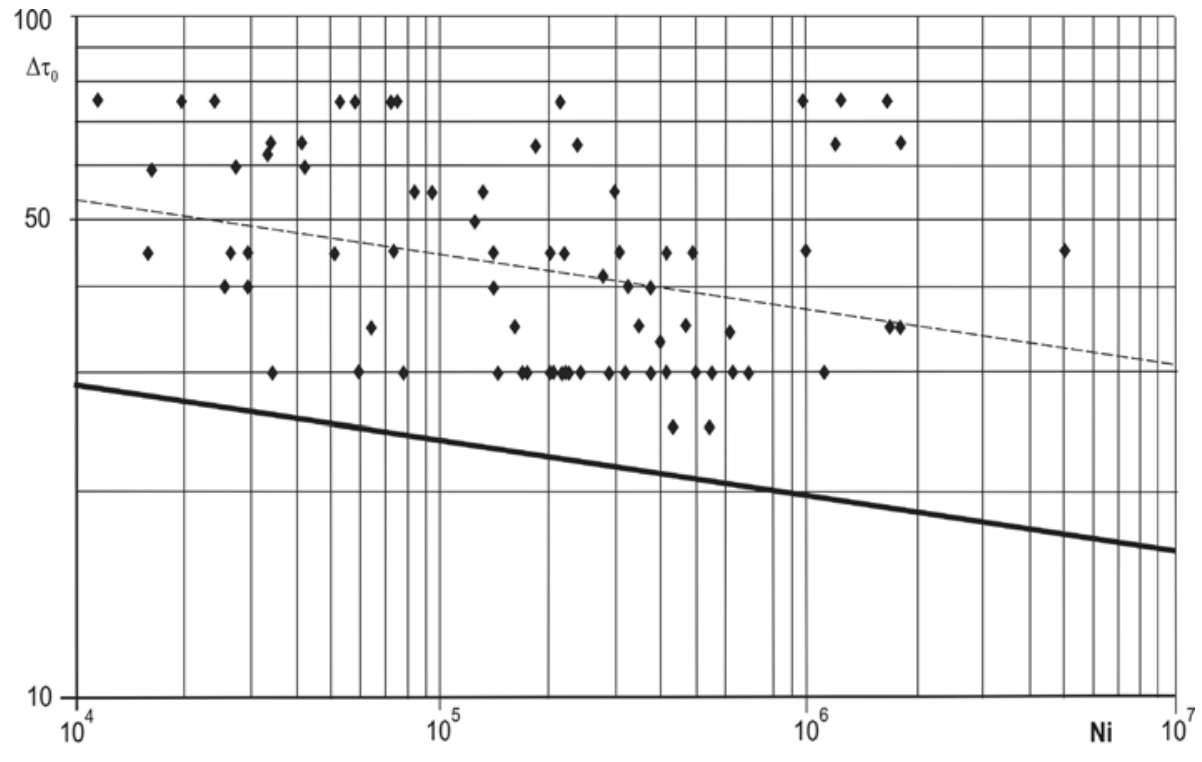

$\log \Delta \tau_{0}=-0,0816 \log \mathrm{Ni}+1,7891795$

Fig 12. Serviceability limit state, $175 \leq \lambda \leq 250$

\subsubsection{Effect of various stress ranges}

If during its lifetime the web is subjected to various stress ranges $\Delta \tau_{i}$ Palmgren-Miner's criterion can be used:

$$
\sum \frac{n_{i}}{N_{i}} \leq 1
$$

where $n_{i}$ is the actual number of loading cycles for the stress level $\Delta \tau_{i}$ and $N_{i}$ is the life, determined from the above S-N curves, of the web determined on the as- sumption that $\Delta \tau_{i}$ is the only loading to which the breathing web is subjected during its whole lifetime.

\subsubsection{Fatigue assessment of breathing webs}

The fatigue assessment of breathing webs should then proceed as follows:

- The first limit state, connected with fatigue failure, shall not be reached before the whole planned life of the structure has been exploited. 
- The other limit state, related to the (experimentally observable) initiation of the first- fatigue-throughcrack, governs the maximum time before which the first inspection of the girder for potential fatigue cracks needs to be carried out.

If no fatigue fissures are found during the inspection, the useful life of the girder can be extended until another inspection is conducted after one half of the time period to the first inspection (this reflecting the fact that the degree of cumulative damage in the breathing web is then larger than during the first period). Failing to detect any fatigue cracks even then, the system of inspections can be extended in the same way. If, and when, a fatigue crack is detected, it shall be carefully measured via frequent enough inspections - with the view to find out whether it (i) propagates or (ii) has stabilised.

The results of the two checks mentioned above will decide whether some retrofitting of the girder is necessary.

\section{Conclusions}

The main conclusions drawn from the authors' experimental investigation into the "breathing" phenomenon and fatigue limit state of steel girders subjected to many times repeated predominantly shear are as follows:

- The main impact of the cumulative damage process in the "breathing" web was the initiation and propagation of fatigue cracks, which almost always develop at the toes of the filled welds connecting the "breathing" web with the girder flanges and stiffeners.

- Most girders exhibited a typical shear failure mode, large buckles developing along the tension diagonal and plastic zones becoming manifest in the girder flanges. In the end, when the main fatigue crack cut the tension band, the girder behaved, and failed, like ones having a large opening in the web.

- The fatigue behaviour and limit state of the girders were mainly influenced by (i) the geometry of the girder (in particular by the depth-to-thickness ratio of the web and the size of the flanges), (ii) the loading regime (especially by the shear force range), (iii) by the shape and magnitude of web imperfections, and (iv) the quality level of the fillet welds connecting the "breathing" web with the girder flanges and stiffeners.

- Even though several design approaches are possible, the authors, having at their disposal a large number of their own fatigue tests and having analysed their results, decided to establish S-N curves directly based on their experimental results. In so doing, two limit states were introduced: (i) the fatigue limit state (related to the fatigue failure of the girder) and (ii) the serviceability limit state (related to the /experimentally observable/ initiation of the first fatigue crack.

\section{Acknowledgement}

The authors express their gratitude to (i) the ITAM AS CzR for the support within the project AVOZ 2071913 and (ii) the Czech Science Foundation for the support within the project 103/05/2059.

\section{References}

1. Škaloud, M. and Zörnerová, M. Fatigue behaviour of the breathing webs of steel plate girders. In: Proc of the $18^{\text {th }}$ Czech-Slovak Int Conf on Steel Structures and Bridges, Brno, 1997, p. 59-66.

2. Škaloud, M. and Roberts, T. M. Fatigue crack initiation and propagation in slender webs breathing under repeated loading. In: Proc of the $2^{\text {nd }}$ World Conf on Steel in Construction, San Sebastian, 1998.

3. Škaloud, M.; Zörnerová, M.; Kuhlmann, U. and Spiegelhalder, U. Prague and Stuttgart experimental research on web breathing. In: Proc of the Int Conference Eurosteel'99, Prague, 1999, p. 75-78.

4. Kala, Z.; Kala, J.; Škaloud, M. and Teplý, B. Values of the results of the experimental investigation obtained from a stochastic analysis - the influence of the magnitude and shape of an initial imperfection of the steel beam slender web on its stress. In: Proc of Czech-Slovak Conference "Experiment - Important Source of Knowledge..." (Československá konference "Experiment-významný zdroj poznání...”), Brno, October 2004, p. 153-158 (in Czech).

5. Djubek, J.; Kodnár, R.; Škaloud, M. and Zörnerová, M. Failure mechanism of webs subjected to repeated loading and a theoretical approach to the problem. Stability of Steel Structures. Akadémiai Kiado. Budapest, 1995.

6. Maeda, Y. and Okura, I. Fatigue strength of plate girders in bending considering out-of-plane deformation of the web. In: Proc JSCE, Structural Engineering / Earthquake Engineering, 1(2), 1984, p. 149-159.

7. Okura, I. and Maeda, Y. Analysis of deformation induced fatigue of thin-walled plate girders in shear. In: Proc JSCE, Structural Engineering / Earthquake Engineering, 3, 1985, p. 377-384.

8. Spiegelhalder, U. Zur Materialermüdung infolge Stegatmung. Dissertation, Inst. für Konstruktion und Entwurf, Universität Stuttgart, Dezember 1999 (in German).

9. Duchène, Y. Etude par voie analytique et numérique des effets de la respiration des âmes élancées sur la résistence ultime des poutres métalliques à âme pleine ou en caisson. Thèse, MSM, Université de Liège, 1998 (in French).

10. Maqoui, R. and Škaloud, M. Some remarks in regard to the fatigue analysis of steel plate girders with breathing webs. In: Proc $20^{\text {th }}$ Czech and Slovak Conf "Steel Structures and Bridges", Prague, 2003, p. 397-402.

11. Škaloud, M. and Zörnerová, M. The fatigue limit state of thin-walled steel girders subjected to repeated loading. In: Proc of the Fourth Int Conf on Thin-Walled Structures, Loughborough, UK, 2004, p. 515-522. 


\section{PLIENINIŲ TILTO SIJŲ „ALSUOJANČIŲ“ SIENELIŲ NUOVARGIO BŪSENA}

\section{M. Škaloud and M. Zörnerová}

\section{Santrauka}

Plonasienių plieninių sijų, apkrautų kartotinemis apkrovomis, ribinis būvis iš dalies yra veikiamas didejjančio sijos sienelès, „alsuojančios“ nuo kartotinų apkrovų, irimo. Remdamiesi Prahos teorinès ir taikomosios mechanikos institute savo atliktais bandymų rezultatais autoriai: 1) aptaria ịvairius požiūrius į minètų sijų nuovargio ribinių būvių nustatymą; 2) pagrindžia kitų tyrinètojų pasiūlytus projektavimo metodus; 3) pateikia savo sudarytų $S-N$ kreivių rinkini, kuris būtų patikima priemonė analizuoti plonasienių sijų su ,alsuojančiomis“ sienelėmis nuovargiui.

Raktažodžiai: kartotinès apkrovos, sienelių „alsavimas“, nuovargio plyšiai, irimo mechanizmas, nuovargio ribinis būvis, $S-N$ kreivès.

Miroslav ŠKALOUD. A chief scientific officer at the Institute of Theoretical and Applied Mechanics of the Academy of Sciences of the Czech Republic and professor at two Czech technical universities. A founding member, a member of the Council and chairman of the Nomination Committee of the Czech Academy of Engineering. A member of 6 intern and 9 Czech working commissions, committees and task groups. Dr HC of two foreign (Liege and Budapest) universities, winner of several prizes (including Czechoslovak State Prize), and recipient of a number of Czech and foreign distinctions. His research and other professional interests include structural analysis, in particular of steel structures, stability problems, the behaviour and limit states of thin-walled structures, the fatigue performance of bridges and similar systems.

Marie ZÖRNEROVÁ. A principal scientific officer at the Institute of Theoretical and Applied Mechanics of the Academy of Sciences of the Czech Republic. A member of IABSE. Member of the team which twice received the Prize of the Czechoslovak Academy of Sciences. Her research interests include the stability and post-critical behaviour of thinwalled steel structures and the fatigue behaviour of structures. 